\title{
El Régimen Internacional de las Obligaciones Extracontractuales
}

\author{
por el Dr. EDISON GONZALES LAPEYRE*
}

A) Soluciones teóricas; 1.- Concepto; II.- Planteamiento del problema; III.- Ley aplicable; IV.- Sistema de la ley personal; V. - Sistema contractualista; VI. - Sistema de la lex fori; VII.- Sistema de la lex loci; VIII. - Sistema mixto de aplicación combinada de lex loci y lex fori; IX. - Soluciones recientes; X. - Nuevas teorias sobre las obligaciones cuasi-contractuales; XI. - Soluciones en materia de obligaciones delictuales; XII.- Nuestra opinión.

B) Soluciones positivas; XIII. - Tratado de Derecho Civil de 1889; XIV.- Tratado de Derecho Civil de 1940; XV.- Código Bustamante.

El estudio del régimen internacional de las obligaciones extracontractuales ofrece gran interés por la revisión de conceptos que se está realizando, últimamente, sobre el tema.

Es indudable que el embate de las teocias renovadoras ha hecho resquebrajar la estructura doctrinaria tradicional; en especial en materia de cbligaciones resultantes de la responsabilidad extracontractual en el Derecho Privado Internacional.

En este trabajo intentamos dar una visión elemental de las principales cuestiones que plantea $y$ de las soluciones teóricas y positivas que se han propuesto sobre el tema en nuestra disciplina.

- Abogado. Asp. Profesor de la Facultad de Derecho y Ciencias Sociales de la Universided de Montevideo (Uruguay). 


\section{A) SOLUCIONES TEORICAS}

I.- Concepto- - Genéricamente, deberiamos considerar incluidas dertro del concepto de obligaciones extracontractuales a todas aquelias que na. cen sin convención, es decir, a las obligacicnes delictuaies, cuasidelictuales. cuasicontractua'es y a las puramente legales, como las que resultan de las relaciones de familia, del régimen de los bienes, etc. Sin embargo, no examinaremos estas últimas, por cuanto ellas no son más que elementos constitutivos del régimen de los derechos reales o familiares y deben considerarse regidas por las normas propias, correspondientes a esos institutos ${ }^{1}$. Este estudio, recaerá, en consecuencia, esencialmente sobre las obligaciones que resultan de delitos, cuasidelitos y cuasicontratos.

II. - Planteamiento del problema. - Una vez calificada la relación jurídica extranacional como correspondiente al tipo de obligación que estamos examinando ${ }^{2}$, debemos determinar cuál es la ley más adecuada para regirla.

III.- Ley aplicable, - Se han propuesto diversas soluciones en un proceso dostrinario que culminó con el predominio y la aceptación mayoritaria de una posición fundada en un respeto estricto al principio de la ley local, tesis que podemos considerar como la tradicional clásica en la materia.

Recientemente, se ha producido un movimiento teórico de revisión que pretende resolver la cuestión sin ceñirse tan estrechamente a criterios terrịtorialistas.

IV.- Sistema de la ley personal-- Según este sistema la obligación extracontractual debe regirse por la ley personal de los sujetos de la misma (activo o/y pasivo). Se funda en los argumentos clásicos de la doctrina de la persona'idad del derecho. Las leyes de un pais siguen a los nacionales del mismo, rigiéndolos por su carácter de tales, sin atender al territorio del Estado en que se encuentren.

1 Conf. VICO, Curso de Derecho Internacional Privado, T. I. p. 370, No 71, 4h ed. Buenos Aires 1959; BATIFFOL. Traité Elémentaire de D. I. P. $3^{*}$ ed. N 561, p. 160; BOUREL Pierre, "Les eonflits de lois en matiére d'obliçations extracontractuelles", Paris 1961. No 1, p. 7. Este fue el criterio que se siguió en la redacción del art. 43 del Tratado de Derecho Civil de Montevideo de 1 SÁ0 (V. infra No XIV).

2 Al respecto se replantea, como en teoria general de la calficación, la procedencia o improcedencia de la aplicación de la lex fori. H. MAZEAUD. "Conflits de lois et compétence internationale dans le domaine de la responsabilité civile délictuelle et quasi-délictuelle". Rev. Crit. de D. Int., 1934, p. 379, N 3, se inclina categóricamente por la calificación lege fori, al expresar: "Todo conflicto de calificaciones se resuelve por la aplicaciôn de la lex fori. El juez debe calificar de acuerdo a su propia ley. Serã pues, ap̧licando los principios de nuestro derecho que los tribunales franceses decidirán si la responsabilidad comprometida es delictual o contractual"; Conf. ARMINJON, Frécis de D. 1. F., 2a. ed. T. I., $N^{\circ}$ 63. p. 144;.BARTIN, Principes, T. I. p. 228.- ALFONSIN por su pärte, rechaza la calificación lége fori, inclinándose por la solución: exegêtica $e$ in ordine; vecise Teoria del derecho privado internacional, Montevidec 1955, p. 390 y "Régimen patrimonial del matrimonio", Rev. Fac. de Der. Montevideo. Nes. 3 y 4. p. 376. 
En ese sentido, la tesis personalista del derecho tiene alcances distintos. Algunos autores la han considerado de aplicación rigurosa a todo tipo de obligaciones extracontractuales en aplicación del principio de que el derecho de un Estado se aplica exslusivamente a todos los nacionales de ese pais y dentro de las diversas alternativas que ofece la teoria de la personalidad del derecho ${ }^{3}$, se han inclinado por la solución de la nacionalidad del deudor ${ }^{4}$. En cambio otros, la han considerado viable, exclusivamente para el caso de que la lex loci delicti ofrezca inconvenientes insalvables en su aplicación ${ }^{3}$.

Crítica- Surge inmediatamente la falta de sustento juridico de esta teoria, como se desprende de las siguientes consideraciones:

a) en cuanto a su fundamento general, porque es indudable que el poder etático se ejerce en todo el territorio del pais, sin discriminar con relación a la nacionalidad de sus pobiadores y

b) en lo que se refiere a su aplicación particular, al tipo de relación juridica que examinamos, en virtud de que, aún los más fervientes partidarios del sistema general de la personalidad del derecho la aplican exclusivamente en materia de obligaciones extrapatrimoniales ${ }^{8}$.

V.- Sistema contractualista. - Se pretendió por ciertos autores. con relación exclusiva a las obligaciones nacidas "ex contractu" ", someterlas a las normas que rigen en materia de obligaciones convencionales.

El autor que mejor fundamentó esta tesis fue LAURENT', quien observando la imposibilidad de aplicar el sistema de la autonomía de la voluntad, afirmo que en virtud de que este tipo de obligaciones responde a un "cuasi-concurso de voluntades" se justifica la asimilación al régimen contractual,

3 Es decir, domicilio y/o naclonalidad del deudor o del acreedor, o de ambos acumulativamente.

4 CF. ZITELMANN Internationales Privatrecht II, 1912, p. 528; FRANKENSTEIN, Internationales Privatrecht, II, 1929, p. 360-393, cits, por BOUREL op. cit. p. 17.

b POULleT, Manuel de D. I. P., 3a. ed. Ne 315, p. 363 y No 318, p. 364.

- V. BATIFFOL, Trạité Elémentzire de D. I. P., Paris 1949, N*230, p. 252.

7 Sin embargo, WEISS en su Traité théor, et prat de D.I.P., T. IV, 2a. ed. ps. 415-416, aplica este criterio también para las obligaciones resultantes de delitos y cuasidelitos. En cambio en su Manual de Der. Int. Privado, trad. por ZEBALLOS, Paris 1912, T. II, p. 317, sostiene este criterio exclusivamente para las obligaciones "ex-contractu", midutras que a las restantes les aplica el sistema de la lex loci delicti.

8 LAURENT, D.I.P., T. VIII. ps. 7 y ss. Este autor de conformidad con su criterjo del cuasi-concurso de voluntades, en su proyecto de Código Clvil belgá, insertó esta dispo. sición: "Los cuasicontratos soia regidos por la ley fersonal de las partes si ellas tienen la misma nacionalidad y por la ley donde el cuasicontrato se forma si ellas pertenecen a dos naciones diferentes". 
Critica.-- Este criterio, que tuvo otros sostenedores ${ }^{\circ}$, carece de todo fundamento por cuanto es indiscutible la naturaleza distinta de la obligación extracontractual con relación a la que resulta de actos convencionales ${ }^{20}$. Por otra parte, como destaca MIAJA DE LA MUELA "1, "tropieza con grandes dificultades en la práctica por la imposibilidad de localizar un querer que no ha sido declarado y que muchas veces no existe.

VI.- Sistema de la lex fori.- Debe aplicarse, según esta tesis, a la obligación extracontractual, la ley del Estado al cual pertenece el tribunal encargado de resolver el litigio planteado.

Mereció la aceptación - en materia de delitos- de autores del prestigio de SAVIGNY ${ }^{12}$ y WAECHTER ${ }^{13}$, quienes se fundaron, para defender esta tesis, en especial, en la premisa de que las disposiciones referentes a ilícitos tienen un carácter imperativo que impide al juez aplicar una norma extranjera. Obtuvo también el apoyo de algunos autores ${ }^{14}$ con relación a las obligaciones cuasicontractuales, pero, en generai, en virtud de estrechos criterios territorialistas.

Hace tres décadas, esta posición fue retemada por Henri MAZEAUD ${ }^{\text {is }}$ manejando dos argumentos principales:

a) de carácter práctico, que resulta de que con la aplicación del sistema de la lex fori se eludirian los inconvenientes que se provocan al aplicar la lex loci delicti, cuando el lugar donde se perpetró el delito es imposible de determinar con certidumbre o cuando el mismo se ha cometido en diversos paises ${ }^{16} \mathrm{y}$

b) de carácter juridico, que surge de considerar todo lo concerniente a lo delictual y cuasidelictual de orden público internacional, en virtud de lo cual las normas nacionales reguladoras de este tipo de obligaciones desplazarian a las extranjeras normalmente aplicables ${ }^{27}$.

- DeSPagneT, Précis de D.I.P. 2a. ed., Paris 1891, p. 511, No 509; SURVILLE, Ccurs elémentaire de D.I.P., 7a. ed., Paris 1925, p. 373.374, No 262; SAVIGNY, Sistema de Derecho Romano Actual. T. VI, Madrid 1879, p. 288.

10 V. PEIRANO FAZIO J., Responsabilidad Extracontractual, Montevideo, 1954, ps. 53-96.

11 MiAjA DE LA MUELA, Der. Int. Privado, Madrid 1955, T. II, p. 239.

12 SAVIGNY, Cours de Droit Romain, 2a, ed., 1860, trad. GUENOUX, No 374, ps. 274-275; V. ALFONSIN, Teoria del D.P.I., N 98, llamada N* 21.

13 WAECHTER, Archiv. fur civilistische Praxis. T. XXV, 1892, p. 392, cit, por BOUREL, Op. cit. p. 20

is VALERY, Manuel de D.I.P., No 671, p. y.u.

15 MAZEAUD $H$. op. cit. p. 376 y ss.

16 MAZEAUD H. op. cit. v. p. 380, No 5, llamada $\mathrm{N}^{*} 1$.

17 MAZEAUD, $H$. op. cit. p. 385, No 12, hace acopio también, para el derecho francés del art. 3, inc. 19 del Código Napoleón. 
El sistema de la lex fori ha sido sostenido por importantes autores en Latino-América ${ }^{18}$ y es el que se sigue actua ${ }^{\top}$ mente en la U.R.S.S. ${ }^{19}$.

Crítica. - Indudablemente, el argumento de carácter práctico que efectúa MAZEAUD para fundamentar su posición doctrinaria es de eficacia, por cuanto la determinación del lugar donde el delito o cuasidelito se ha cometido constituye, en muchos casos, un problema dificil de resolver. Pero e! mismo no tiene la soỉidez necesaria como para respaldar por si solo esta posición. Y ello, por cuanto Jas razones juridicas que esgrime este autor, parten de una fa'sa y exagerada conrepción del orden público internacional co. Sólo podria prosperar esta interpretación, para el caso de una colisión flagrante y grosera entie la norma extranjera y la nacional del tribunal competente ${ }^{2 t}$

Al respesto, la Doctrina contemporáneu tiende a restringir la extensión del orden público internacional, a fin de obtener soluciones armónicas en cuanto a la regulación de las relaciones juridicas extranacionales ${ }^{22}$. Por dra parte de admitirse este criterio, deberiamos conzluir en que la aplicación de la ley del tribunal se efectuaria, no como una solución normal -esto es, pretendiendo darle a la relación la norma más adecuada que la rija er todo lugar - sino que dicho criterio jugaria a titulo excepcional ${ }^{2 ?}$.

VII,- Sistema de la lex loci.- Esta solución es la que ha merecido el mayor apoyo por parte de la Doctrina; especialmente en Francia que la ha recogido en el art. 3 inc. $1^{\circ}$ del Código Civil ${ }^{24}$.

Se han esgrimido argumentos de diversa indole en favor de esta posición. Los fundamentales son -a nuestro entender- los siguientes:

a) de çrácter jurídico, que ofrece distintas variantes, 1) asi GOLDSCHMIDT ${ }^{25}$ se inclina por la lex loci (refiriéndose en forma exciusiva a las obligaciones delictuales y cuasicielictuales) por entender que las normas reguladoras de los actos ilicitos son de carácter penal en un sentido lato $y$ en consecuencia, deben aplicarse territorialmente; 2) otros autores, v. g. BATIFFOL ${ }^{26}$, argumentan que la obligación ex-

is ALCORTA, Curso de D.I.P., T. II, 2a. ed Buenos Aires 1927, p. 346; BUSTA. MANTE, Der. Int. Privado, La Habana 1931, T. II, p. 314.

io MAKAROV, Précis de D.I.P., trad. Noldz y Pereverzeff, p. 305.

20 NIBOYET, Traité de D.I.P. Français, Paris 1948, T. V. No 1427, llamada N`3, expresa al respecto: "Hay en esta competencia de là lex fori, una confusión ontre el orden público y lo que es totalmente diferente, la ley de policia.

21 BOUREL, op. cit. par. 3, p. 21.

23 BARTIN. Principes, T. II, par. 333. ps. 397-398; NIBOYET, Traité, T. V. p. 157; BATIFFOL, Traité, 3a. ed., No 559, p. 616.

23 Lo que paradöjlcamente deberia conducir a una interpretación restrictiva y no extensiva.

24 Sin embargo - como hemos visto ut-supra N6. VI, llam. No 17- esta disposicín constituye uno de los argumentos de H. MAZEAUD para sostener la competencia de la lex tort.

23 GOLDSCHMIDT, Sistema y Filosofia del Derecho Internacional Privado, Buenos Aires 195., T. II, p. 454.

2ه BATIFFOL, Traitẻ elémentaire de D.1.P., Paris 1949, N' 285, p. 305. 
tracontractual es de carácter legal y tiene su razón de ser en un hecho, que el legislador reglamenta imperátivamente, transformándolo en juridico y "tratándose de una relación juridica que no puede ser localizada ni por su sujeto ni por su objeto, debe serlo por su fuènte, el hecho juridico que le ha dado nacimiento, esto es, el delito o el enriquecimiento sin causa. $Y$ esos hechos no presentan otro punto de localización que el lugar dónde se han producido". De modo que, siendo el hecho el fundamento juridico de la relación, debe atenderse al lugar donde éste se produjo para localizar la obligación que de él resulta;

b) de carácter trleológico, fundado en consideraciones de orden social. Se sostiene, por los autores que participan de esta argumentación ${ }^{27}$, que una razón de paz y de seguridad social indica que el orden jurídico de un Estado debe regir todos los hechos que én él se producen $y$, en consecuencia, también aquellos de los que resulta una relación de responsabilidad. En materia de cuasicontratos se argumenta ${ }^{28}$ que existe una razón de utilidad social resultante del heoho de que los cuasicontratos tienen por objeto la conservación de los bienes, lo que indica que debe aplicarse a éstos, la lex loci.

c) de carácter práctico, se hace acopio también ${ }^{29}$ a las ventajas que sesde este punto de vista ofrece el sistema, proporcionando un método senci lo de regulación de la relación jurị́dica, por la via de establecer cono ley aplicable, la correspondiente al lugar de localización natural de la obligación extracontractual.

Por estos fundamentos y atendiendo a que constituye un principio indiscutible, en el estado actual de nuestra dissiplina, que la relación jurídica extranacional debe ser regida en todo lugar por la norma más adecuada, creemos que este sistema es el más aceptable.

El orden juridico más apropiado para regir las consecuencias de un hecho, es aquél que corresponde al país donde el hecho se ha producido y normalmente ha provocado sus efectos. Cada Estado legisla y procede jurisprudencialmente de acuerdo a sus necesidades, de acuerdo a la conciencia social de sus nacionales y de acuerdo a las exigencias de su commercium interno. $\mathrm{Y}$ siendo estos factores los normalmente afectados por el hecho constitutivo de un delito, cuasidelito o cuasicontrato, es lógico concluir que son 'as normas jurídicas die ese país, las más adecuadas para regir, en todo lugar, las obligaciones que de él resulten.

27 PILLET. Traité de D.I.P., T. I. Nos. 21 y ss., ps. 99 y ss; BARTIN, Principes. T. II, p. 287 , FIORE, Clunet, 1900, p. 718.

28 VIZIOZ, La noticn de quasi-contrats. No 73, p. 306.

29 BATIFFOL, op. cit. No 285. p. 332-334. 
VIII.- Sistema mixto de aplicación combinada de lex loci y lex fori. Las dos últimas soluciones examinadas, han merecido, por parte de Inglaterra y Alemania aplicaciones mixtas o combinadas.

En Inglaterra, a partir de un famoso fallo judicial de fines del siglo pasado ${ }^{30}$, la cuestión relativa a los conflictos de leyes en lo referente a ilicitos se resuelve sobre la base de dos premisas: 1) para acordar un derecho de indemnización es necesario que el acto incriminado constituya un delito en el lugar donde fue cometido y que a su vez, los tribunales ingleses le otorguen al damnificado la facultad de accionar ante ellos y 2) ese acto no debe sér "justificable" de acuerdo a la lex loci delicti. Es decir que sólo podrá prosperar una acción indemnizatoria en Inglaterra por un ilicito cometido en el extranjero, cuando por las características del hecho, si hubiese sido cometido en Inglaterra, hubiese merecido igual calificación ${ }^{3 x}$.

En Alemania, la combinación de ambas soluciones (lex fori y lex loci) tiene otros alcances. Al respecto el art. 12 de la Ley de Introducción al Código Civil Alemán, prescribe que: "No es posible en virtud de un acto ilicito cometido en el extranjero hacer valer contra un alemán, derechos más amplios que los establecidos por las leyes alemanas". Esta disposición no implica otra cosa que una protección a los wacionales alemanes contra la eficacia extraterritorial de la lex loci, o sea que la lex fori actuaria como un limite a la amplitud o extensión de las normas correspondientes al pais donde el ilícito se cometió y en exclusiva protección de los nacionales alemanes.

IX.- Soluciones recientes.- Ultimamente la Doctrina ha reaccionado contra el criterio predominante de aplicación indiscriminada y rígida de la lex doci. El resultado del nuevo enfoque teórico ha sido un sistema elástico. que tiene en cuenta, casuisticamente, las caracteristicas de la relación juridica que se pretende regular para determinar la norma aplicable. Se ha apreciado que el sistema de la lex loci, aplicado en forma rigurosa e indiscriminada (a pesar de su simplicidad y sus ventajas desde el punto de vista práctico), encierra un inconveniente de importancia: no suministra una norma, que en forma adecuada, se adapte a las distintas circunstancias y condiciones que se dan en las múltiples variedades que ofrece la obligación extracontractual.

Este movimiento renovador por parte de la Doctrina en el tema que nos ocupa, tiene caracteres distintos de acuerdo a que se trate de obligaciones cuasicontractuales o de obligaciones delictuales. Lo examinaremos pues. separadamente.

X.- Nuevas teorias sobre las obligaciones cuasicontractuales.- Sobre este punto han sido fundamentalmente, los autores alemanes y suizos los que han arribado a conclusiones más importantes. Y ello, en virtud de que en

3n Philips, v. Eyre (1870), Queen's Bench, English Reports.

31 A idéntico tipo de solución acumulativa llega VALERY op. cit. Nos. 674 y ss., y. la ley japonesa de: 15 de junio de 1898 en su art. 1i. (Clunet 1901, p. 641). 
sus respectivos paises el enriquecimiento sin causa es comprensivo de una serie de hipótesis ${ }^{32}$, que le dan una gran amplitud a esta noción. Eso sucede en razón de que en Alemania y Suiza se prescinde de la noción de causa como requisito de vaiide $z^{33}$, con diferencia de otros sistemas como el francés ${ }^{34}$ y el uruguayo ${ }^{35}$, que traen aparejado un concepto más estrecho de este cuasicontrato.

Desechando la posibilidad de que una ley única pudiese regir adecuadamente la relación juridica en estudio, estos autores concluyeron en el sentido de distinguir, para la determinación de la norma aplicable. de acuerdo a la clase de hecho que han dado lugar a' enriquecimiento sin causa. Al respecto, siguiendo a BOUREL ${ }^{36}$, podemos distinguir dos corrientes de opinión:

1) La primera, partidaria de una solución acumulativa, sobre la base de un desmembramiento o segmentación del cuasicontrato en dos partes, una referente a las condiciones de existencia y a la ausencià de causa legitima en el enriquesimiento y la otra, relativa a las caracteristicas del ejercicio de la acción de restitución.

Dentro de esta corriente de opinión ${ }^{37}$. se destacan VON MAYR en Alemania y NIEDERER y SCHONENBERGER en Suiza.

32 V. g. prestaciones que se reclaman por hajer sido efectuadas en virtud de obligar ciones, declarad-.s nulas, arts. 812 v ss. del B. G. B.

s3 GAMARRA Jorge. Estudios sobre obligaciones, Montevideo 1956, № 2, p. 68, drstaca que sobre le base de la noción de causa se han construido dos grandes sistemas: "el alemán, teriendo como base el negocio abstracto, que prescinde de la noción de causa como requisito de valiciez. La causa no es un elemento del negocio abstracto, lo que significa que, aún careciendo de ella, el negocio es válido. Si la atribución patrimonial revela posteriormente falta de causa, no se da una acción de uulidad contra el negocio, que mantiene su eficacia, produciendo sus efectos juridicos normales. El medio de. corregir e:ta anomalia es, precisamenie, el enriquecimiento sin causa. Ello quiere decir que el enriquecimiento sin causa en el derecho germánico exliende su ámbito no solo a la zona extranegocial, sino también, a la propia esfera de los contratos. El sistema opuesto fue e: que siguió el Cócígo Francćs v el nuestro (el Uruguayo), que hizo de la causa uno de los elementos esenciales para la validez de los contratos. Si un contrato carece de causa, el negocio resulta nulo y no ha podido producirse traslación eficaz de biene: de un patrimonio a otro. Por ende la sertencia que p:onuncia la nulidad del negocio tiene naturaleza declarativa. limitåndo:e a acertar la posición del bien, que no ha abandonado el patrimonio del solvens. $\mathrm{La}$ consecuencia de esta concepción es la radicación del enriqueciniento sin causa en la zona del nego. cio juridico".

34 V. RIPERT et TEISSEIRE, Essai d'une théorie de l'enrichissement sans cause en droit civil français, Revue trimestrielle de droit civil 1904, p. 756; ROUAST, L'enrichissemeni sans cause et la jurisprudence civile, Rev. trimestrielle de droit civil, 1922, № 13.

si V. GAMARRA, op. cit. p. 67 y ss. y PEIRAINO FAZIO J.. Curso de obligacicmes, ed. Centrc de Estudiantes de Derecho, Montevideo, 1957, T. II, p. 501 y ss. esp. p. 515 .

36 BOLIREL, op. cit. p. 32.

s7 Tambiên han sostenido soluciones acumulativas, NEUMEYER, Internationales Privatrecht, 1923, par. 36 , p. 32 cit. por BOUREL, op. cit. p. 33; PILLET. Traité pratique, T. II. No 547 bis; ARMINJON, Précis de D.I.P., 4a. ed. No 119, p. 322/323; NIBOYET. Traité T. V, No 1444 , p. 193 y No 1445 p. $194 / 195$. 
Los dos primeros ${ }^{38}$, efectuando el desmembramiento apuntado, sostienen que la ley local debe resolver todo lo concerniente a la extensión y modalidades de este tipo de obligaciones, mientras que la lex causae, esto es, la ley que rige la relación jurídica que sirve de fundamento a la prestación, es la que debe determinar la existencia del enriquecimiento sin causa.

En cambio, SCHONENBERGER ${ }^{30}$ efectúa una triple segmentación. distinguiendo:

a) lo relativo a la determinación de la existen zia del enriquecimiento, que debe ser regulada si se trata de créditos por la ley correspondiente a dicho crédito y si se trata de derechos reales por la lex ret sitae;

b) lo referente a determinar si ese en:iquecimiento se ha efectuado sin causa, que lo somete en principio a ia lex causae, al afirmar que debe regirse para el caso de un contrato de venta o de donación por la lay pertinente para determinar la validez de dicho vinculo y para el caso de un pago indebido por la ley que deberia regir la deuda pretendida, y

c) lo relativo a la extensión, contenido y condiziones de eiercicio de la acción de restitución, que se rige por la ley del lugar donde se produjo el hecho generador del cuasicontrato.

2) La segunda, tiene su fundamento teórico en la variedad de circunstancias que ofrece la acción proveniente del enriquecimiento injusto y se pretende, en el ámbito del derecho privado internacional, obtener soluciones que se adapten a esas distintas situaciones, rechazando, en consecuencia, todo tipo de criterios únicos. ZWEIGERT ${ }^{* 0}$, observa que en el Derecho Comparado la acción, a que da lugar la obligación extracontractual en estudio, ofrece tres aspectos distintos: 1) un aspecto de carácter real, en la reivindicación de bienes provocada por la anulación o eaducidad de un contrato en el Derecho Alemán ${ }^{41}$; 2) un aspecto delictual, que resulta de que en el Derecho Inglés, las operaciones de conmixtión, adjunción y especificación son consideradas como delitos, mientras que en el Derecho Alemán, siguen el régimen del enriquecimiento sin causa ${ }^{42}$ y 3) un aspecto

38 VON MAYR, Der Bereichrungsanspruch des deutschen bürgerlichen Rechts, 1903. p. 105 y NIEDERER, Einfürung ir. die al!gemeinen Lehren des I.P.R. 2a. จd. 1956 p. 187. cits. por BOUREL op. cit. p. 32 y 33.

s9 SCHONENBERGER, en OSER-SCHONENBERGER: Kommentar zum Scheizerischen Zivilgesetzbuch, V. Obligationenrecht, 1921, Internationales Privatrecht, Nos. 1^8, 149, 150, p. LXXXXIX, cit. p. BOUREL, op. cit. p. 33.

40 ZWEIGERT, Bereicherungsansprúche in internationales Privatrecht, en Süd-deutsche Juristen-Zeilung, 1947, col. 247 y ss., cit. p. BOUREL op. cit. p. 34.

41 Tener en cuenta las especiales caracteristicas -en esta materia- del Derecho Alemán, v. llam. No 33.

42 Art. 951 B.G.B. 
cuasicontractual, que resulta en el Derecho Inglés cuando por una causa ajena a su voluntad el deudor no ha ejecutado su obligación y que en el Derecho Alemán, se encuentra dentro de las disposiciones relativas a los contratos ${ }^{43}$.

De esta manera, aprecia este autor, atendiendo a las distintas calificaciones que puede merecer la misma relación juridica en distintos Estados y teniendo en cuenta dos situaciones diferentes, propone el siguiente criterio de solución:

a) si el enriquecimiento proviene de una operación aislada, esto es, sin que haya ninguna vinculación entre ei que se empobrece y el que se enriquece, debe regirse la obligacion por la ley del lugar de donde se ha producido la adquisición y

b) si el enriquecimiento tiene por fundamento una obligación preexistente hay que aplizarle la ley correspondiente a dicha obligacion, esto es, la lex causae ${ }^{4}$.

XI. - Soluciones en materia de obligaciones delictuales.-- El mismo fenómeno de descrédito que se está produciendo con relación al principio de la lex loci en materia de obligaciones cuasicontractuales, tiene lugar con relación a las cbligaciones resultantes de delitos y cuasidelitos, aunque con otros alcances.

Podemos distinguir dos tendencias distintas en la materia:

a) pretende simplemente atenuar los efectos y la ap'icación rigurosa de la ley local, mediante la armonizazión de este criterio clásico con el sistema de la determinación del lugar de comisión del ilicito. En ese sentido RABEL, considera que un gran número de delitos deben localizarse de acuerdo a reglas propias, p. ej. los que se cometan por intermedio de la prensa, de la radio, del fraude, de la concurrencia desleal, etc. ${ }^{45}$. Es de gran interés, dentro de esta corriente doztrinaria, la posición de BINDER quier entiende que el ilícito no debe localizarse exclusivamente sobre la base de un criterio material del principio de la lex loci delicti commisi, sino que hay que tener en cuenta el medio social a que el mismo se encuentra "enraizado" $46, y$

b) considera que ciertos delitos están scmetidos en cuanto a su régimen legal a un fuero de atracción "sui generis" por parte de las normas

43 Art. 328 B.G.B.

4 En forma similar a ZWEIGERT, se expide BALASTER, Die ungerechfertigte Bereicherung in internationalen Privatrecht, Zurich, 1955 , p. 60 y ss. Al respecto remitimos al examen que de esta teoria ha hecho BOUREL en su excelente monografia, que hemos ceguido, especialmente, con relación a los autcres de lengua germana.

45 RABEL. The Conflict of laws, T. II, p. 301 y ss.

46 BINDER, Zur auflockerun des Delikstatuts Rabelsz, 1955, p. 480 y ss. cit. p. BOUREL cp. cit. p. 40. 
competentes que rigen la relación juridica subyacente ${ }^{47}$. Se observa por estos autores ${ }^{48}$ que muy a menudo, el ilicito aparece estrechamente vinculado a un conglomerado de relaciones de carácter familiar, real, contractual, etc. y que en virtud de eso, debe regirse los mismos. por las normas competentes para regular los institutos a que están vinculados.

El precursor de esta posición es BROCHER quien afirmaba a fines del siglo pasado que "cada vez que el delito está sometido a la atracción de un estatuto especial, los hechos deben entrar, como accesorios, dentro de la competencia del estatuto de que forman parte por los efectos que deben producir o por el sujeto al cual se refieren" ${ }^{29}$.

Por último, MORRIS, en una solución.casuistica, propone aplicar al régimen de las obligaciones delictuales y cuasidelictuales, la solución inglesa en materia de contratos ${ }^{50}$. Esto es, aplicarle "mutatis-mutandi", al régimen de los delitos y cuasidelitos, la teoria de la proper law of the con'ract ${ }^{51}$. De esta manera se preconiza la búsqueda para cada ilicito de la norma que mejor se adapte a las circunstancias variadas que pueden darse en los hechos delictuosos, sin ceñirse, como la posición clásica, a una aplicación rigurosa del principio de la lex loci delicti commisi ${ }^{52}$.

XII.- Nuestra opinión. - Examinadas en sus rasgos fundamentales las distintas soluciones que la Doctrina está elaborando últimamente en materia de obligaciones extracontrastuales, se observa que, en la mayoria de los sistemas que se preconizan hay un equivocado enfoque del problema, un falso punto de partida. Eso lleva, lógicamente, a conclusiones erróneas.

47 Nótese la similitud de esta solución con la preconizada por ZWEIGERT, v. ut-

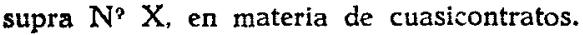

18 NEUHAUS, Rabelsz, XVII. 1951, p. 651 y SĆHNITZER, Handbuch des IPR 2a. ed. 1944, 'l. II, p. 598, cits. p. BOUREL, p. 41.

49. BROCHER, Cours de D.I.P. suivant les principes consacrés par le drott positif français, T. II, $1883, N^{p} 182$, p. 144.

so MORRIS J. H. C., The proper law of a tort, Harvard Law Review, abril 1951, vol. 64, p. 881 y ss.

51 Precisamente denominó a su sistema. "The proper law of tort".

52 Al respecto, da el siguiente ejemplo, op. rit. p. 885, que fue tomado por BINDER para justificar su teoria: un coleģic mixto estadounidense organiza una coloria de vacaciones en la región del Quebec, en Canadá. Esta región está completamente - aislada, no existiendo otros seres humanos en un área de cincuenta millas. Durante la estadia una alumna es seducida por uno de sus compañeros y otra mordida por un perro. Estes dos inci-. dentes se producen por la sola negligencia de los encargados de la colonia. Por otra parte, todos los n:iembros de la misma, organizadores y alumnos estän domiciliados en los Estados Unidos y en el mismo Estado. Afirma MORRIS que mediante tales circunstancias, sería absurdo someter la acción de responsabilidad a la ley canadiense del lugar de comisión de los hechos, cuando en realidad, todos los elementos esenciales del litigio están insertadoz en el orden juridicu estadounidense. 
Asi algunos autores, v, g. SCHONENBERGER, VON MAYR, NIEDERER ${ }^{53}$, incurren en el error de examinar como cuestiones constitutivas de la categoria, obligación extracontractual, circunstancias que están dentro del probiema previo $-y$ en consecuencia distinto de calificación que debe resolverse de acuerdo a las soluciones propias de esta materia.

La primera operación a realizar por el jurista es la de calificar la rela. ción juridica y precisar concretamente -en su caso- el tipo de obligación extracontractual de que se trata. Luego si, deberá determinar la ley que debe regirla y la jurisdicción competente.

Ambas operaciones están regidas por principios distintos y propios. La calificación debe efectuarse de acuerdo al sistema que se adopte en la materia ${ }^{54}$ y en forma previa y no concomitantemente con la operación tendiente a determinar la ley aplicable y la jurisdicción competente para cada categoria. La razón es de orden lógico, para poder aplicarle normas especificas y prozedimientos propios, a esta última operación, es necesario haber precisado anteriormente la categoria objeto de la misma, esto es, haber calificado la relación juridica de la referencia.

En cuanto a las teorías que pretenden regir este tipo de obligaciones por las normas correspondientes a la relación jurídica subyacente o a los institutos a que están vinculados por conexión o accesoriedad, v. g. BROCHER, NEUHAUS, SCHNITZER, parcialmente ZWEIGERT, creemos que esa conexión o accesoriedad no puede constituir razón suficiente para determinar el régimen normativo de la obligación. Constatado que constituye una categoria, de ello resulta su naturaleza propia y es necesario procurarle la norma que sea más adecuada a sus caracteristicas especificas y no someterla a otras disposiciones que se refieren a institutos que tienen distinta estructura sustantiva.

Si en materia de obligaciones contractuales - donde podrían encontrarse argumentos más eficaces - observamos ${ }^{55}$ que la accesoriedad es rechazada en la actualidad, como circunstancia determinante de la legislación competente, con mayor razón debemos descartarla en este tipo de obligaciones.

Por último, en cuanto a las teorias casuisticas, v. g. MORRIS, se reiteran aqui los mismos inconvenientes que en materia de obligaciones contractuales ofrece la tesis de las soluciones analiticas libres. Al respecto, JITTA. adelantando. una objeción a su propia teoria, exprésó: "Esta solución está lejos de ser plenamente satisfactoria: lo que el derecho gana en elasticidad lo pierde en certidumbre" ${ }^{56}$. Consideramos que "mutatis mutandi" esta afirmación es aplicable al sistema de la "proper law of tort".

53 V. ut-supra $\mathrm{N} 8 \mathrm{X}$.

s. V. ut-supra No III, llam. N* 2.

*.. V. GONZALEZ LAPEYRE E., Los contratos accesorios en el D.P.I., Rev. Fac. de Derecho, Montevideo, año XII, Nos. 3-4, p. 911, No III.

6. IITTA, "La substance des obligations datis le D.I.P., La Haya 1906-1907. T. I. p. 19: ALFONSIN, Régimen Internacional de los contratos, Ne 73, p. 198. 
A nuestro entender el principio de la ley local en materia de obligaciones cuasicontractua'es, delictuales y cuasidelictuales mantiene totalmente su imperio. Ofrece, es cierto, dificultades --en algunos casos- de localización ${ }^{57}$ y al respecto, consideramos con BINDER, que no debe atenderse, en forma exclusiva, a criterios materiales y que es necesario tener en cuenta consideraciones de carácter social. De esta manera este criterio adquiere la suficiente elasticidad de que careceria de ser aplicado en forma estrictamente material, lo que aunado a su natural certidumbre lo convierte en el sistema más adecuado.

\section{B) SOLUCIONES POSITIVAS}

Conjuntamente con las soluciones positivas peruanas sobre el punto - Tratado de Derecho Civil de Montevideo de 1889 y Código Bustamanteexaminaremos también, el Tratado de Derecho Civil de Montevideo de 1940 porque habiendo sido suscrito por el Perú, es de esperar una próxima ratificación por parte de este pais.

XIII. - Tratado de Derecho Civil de $1889^{58}$ - Establece en su art. 38: "Las obligaciones que nacen sin convención se rigen por la ley del lugar donde se produjo el hecho licito o ilicito de que proceden". Se admite pues, el criterio de la lex loci, sin hacerse referencia a las obligaciones puramente legales ${ }^{59}$.

De las actas del 1er. Congreso Sud-Americano de Montevideo, no surgen elementos de juicio sobre el fundamento teórico de esta disposición. Sólo se puede apreciar a través de ellas ${ }^{60}$ que originariamente el art. 38 es taba redactado de la siguiente manera: "Las obiigaciones que nacen sin convención deben cumplirse en el lugar donde se produjo el hecho lícito o ilicito de que proceden". De esa redacción primitiva, que fue modificada posterior. mente puede deducirse que, erróneamente, $e^{1}$ proyecto presentado por la comisión presidida por el delegado argentino Dr. MANUEL QUINTANA intentó, sobre la base de una pretensa analogia entre las obligaciones contractuales y las extracontractuales, regir a estas últimas por la ley del cumplimiento, aunque estableciendo, por las vías de una presunción absoluta, que las obligaciones nacidas sin convención debian "cumplirse en el lugar donde se produjo el hecho licito o ilicito de que proceden".

57 Este punto, con sus dificultades apuntadas especialmente por VENTURINI, "Note sulla disciplina di diritto internazionale privato delle obligazionl da illecito" en Scritti de Diritto Internazionale in onore di Tumaso Perassl, p. 367 y por BOUREL op. cit. p. 57." será objeto de un futuro trabajo.

58 Rige para Perú con Argentina, Bolivia, Colombia, Paraguay y Uruguay.

59 V. ut-supra $\mathrm{N}^{0} 1$.

6o Acras y Tratados celebrados por el Congreso Internacional de Montevideo, Mon. tevideo 1889. Acta No 29, p. 693. 
Indudablemente, fue más acertado el criterio que primó en definitiva. Al respecto, consideramos que fue la notoria influencia de GONZALO RAMIREZ la que llevó a -los congresistas de 1889 por el camino recto. Coadyuvando esta afirmación, observamos que en el art. 14 de su Proyecto de Código Internacional ${ }^{61}$ plasmó prácticamente la misma norma - -perfeccionada terminológicamente luego- del art. 38 del Tratado.

XIV.- Tratado de Derecho Civil de 1940 ${ }^{62}$. - El art. 43 establece: "Las obligaciones que nacen sin convención, se rigen por la ley del lugar en donde se produjo el hecho lícito o ilicito de que proceden y, en su caso, por la ley que regula las relaciones juridicas a que responden".

Se sigue pues el mismo criterio del ler. Congreso Sud-Americano, con la particularidad de establecer el régimen correspondiente a las obligaciones puramente legales, que se sometan a la ley que regula la relación jurídica a que responden".

Al respecto, interesa destacar que el delegado uruguayo Dr. VARELA solicitó que se dejase constancia en actas de la posición sostenida por el delegado argentino Dr. VICO, quien expresó: "I a Delegación Argentina entiende que las obiigaciones que no nacen de hechos licitos o ilicitos, nacen de otro orden de re'aciones jurídicas impuestas por la ley. Asi, por ejemplo: es la ley la que da origen a la obligación de prestarse alimentos entre parientes y a la obligación de condominio forzoso de los muros divisorios. La primera de dichas obligaciones legales, o sea la relación jurídica entre los parientes liamados a dar y a recibir alimentos, es de carácter personal; la segunda, o sea la réación de comunidad entre los propietarios colindantes, es de orden real. Contemplando la diversa naturaleza de ambas obligaciones, se propuso y se adoptó en la primera etapa de los trabajos del Congreso (en 1939) la fórmula final del artículo: "y en su caso, por la ley que regula las relaciones jurídicas a que responden ${ }^{63}$.

XV.- Código Bustamante ${ }^{64}$ - En virtud de una redacción ambigua y poco técnica sobre el punto, ofrece diversas dudas en su interpretación.

En primer lugar - y ese es su principal mérito- consagra un criterio de clasificación y calificación de las obligaciones al establecer en su art. 164: "El concepto y clasificación de las obligaciones se sujetan a la ley territorial". Sigue pues, el principio de la ley local en esta materia.

Posteriormente en su art. 165, hace referencia a las "obligaciones derivadas de la ley" regulándolas por el derecho que las haya establecido. Se

61 RAMIREZ, Gonzalo. Proyecto de Código de Derecho Internacional Privado y su comentario, Buenos Aires 1888 , F. 28.

62 Rige exclusivamente entre Argentina, Uruguay y Paraguay.

63 Cit. p. BUSTAMANTE y RIVERO. El Tratado de Derecho Civil Internaciona! de 1940, Montevideo 1942, p. 123.

64 Vigente entre Perú, Guatemala. Nicaragua, Panamá, Honciuras, Repüblica Dominicana, Bolivia, Brasil, Costa Rica, Chile, El Salvador, Haiti y Venezuela, habiéndolo ratificado con reservas los últimos siete citados. 
trata de una norma de difícil interpretación, porque esa expresión "deriva. das de la ley", puede tener distintos significados.

Genéricamente, todas las obligaciones derivan de la ley; con un criterio más estrecho, puedé distinguirse entre obligaciones contractuales y obligaciones de origen legal, incluyendo dentro $\mathrm{d}$ : éstas, las cuasicontractuales, las delictuales, las cuasideliatua'es y las de carácter puramente legal a que hizo referencia VICO en el $2^{\circ}$ Congreso Sud-Americano de Montevideo ${ }^{65}$ y son reguladas en el art. 43 parte final del Tratado de Derecho Civil de 1940; y por último, con un criterio estricto, podria considerarse que la norma que examinamos se remite exclusivamente a esta última categoría de obligaciones.

La posición que considera que el artículo en estudio se refiere a las obligaciones cuasi contractuales está abonada por el hecho de que posteriormente no se haya estab'ecido esperificamente el régimen internacional de este tipo de obligaciones y, asimismo, a que en la época en que se redactó esta disposición, recién se empezaban a afinar los conceptos sobre el punto.

En los articulos 167 y 168 se regulan las obligaciones de origen delictual y cuasidelictual. De dichas disposiciones resulta la siguiente discriminación:

a) si se trata de hechos ilicitos penados por la ley, las obligaciones que de e'los resultan se rigen por el derecho correspondiente que tipificó la infracción, determinando la pena y

b) si se trata de actos $u$ omisiones no penados por la ley, se regirán, las obligaciones que de ellos resulten, po: la ley del lugar en que se hubiere incurrido en la negligencia o en la culpa que las origine.

El art. 168, al hab'ar de actos u omisiones no penados por la ley, agrega "en que intervenga culpa o negligencia". De esta disposición parece desprenderse la exclusión de los actos dolosos, efectuada por haberse entendido que todos los actos dolosos estaban incluídos en la disposición del art. 167. Pero ello no es totalmente asi, por cuanto pueden haber actos u omisiones dolosos, no tipificados ni sancionados por la ley penal. Con relación a ellos consideramos que deben regirse de acuerdo a lo prescripto en el art. 168:

a) porque en la disposición anterior, el tratado internacional se refiere exclusivamente, en nuestro criterio, a las obligaciones que resultan de delitos o faltas tipificadas penalmente $y$

b) porque del contexto de ambas disposiciones resulta que se intentó en el art. 168 incluir todas las obligaciones de origen delictual y cuasidelictual no regidas en el art. 167.

Es necesirio destacar que GARCIA CALDERON en un somero comentario a estas disposiciones is expresa: "El Código Bustamante distingue

os V. ut-supra N• XIV.

- GARCIA CALDERON M., Repertorio de Derecho Internacional Privado, Lima 1962, T. II, P. 182. 
entre las obligaciones contractuales y cuasicontractuales resolviendo en forma diversa sobre unas y otras. Los Tratados de Montevideo, en cambio. someten las obligaciones que nacen sin convención a una sola ley que es la del lugar donde se produjo el hecho ilicito".

Consideramos que esta afirmación, hubo de tener origen en un error de imprenta o de transcripción. De lo que hemos examinado anteriormente y también, del contexto general del comentario de la referencia, se deduce que este jurista quiso expresar que en el Código Bustamante se distingue entre obligaciones cuasicontractuales y obligaciones delictuales y cuasidelictuales. mientras que en los Tratados de Montevideo, se somete a todas ellas a una misma ley. 